\title{
PREVENSI PERILAKU BULLYING PADA SISWA SEKOLAH DASAR MELALUI SOCIAL SKILL TRAINING DAN FAMILY PSYCOEDUCATION DI KOTA PADANG
}

\author{
PREVENTION OF BULLYING BEHAVIOR IN \\ ELEMENTRY SCHOOL STUDENTS THROUGH SOCIAL \\ SKILL TRAINING AND FAMILY PSYCOEDUCATION IN \\ PADANG CITY
}

\author{
Renidayati ${ }^{1}$ \\ 'Poltekkes Kemenkes Padang \\ Jl. Simpang Pondok Kopi Siteba, Padang \\ Email : renidayati72@gmail.com
}

Naskah Masuk: 27-11-2018

Naskah Diterima: 14-12-2018

Naskah Disetujui: 14-12-2018

\begin{abstract}
Bullying seems to have become an integral part of the lives of children today. The high incidence of bullying behavior in primary school-aged children in the family, school, and surrounding environment indicates the need for immediate interventions to address the problem of school-aged children. Some efforts should be made in the form of prevention, treatment and rehabilitations for victims of bullying behavior. One form of intervention that can be developed as an effort to prevent bullying behavior in school-aged children is Social Skill Training and Family Psycho education therapy. Through Social Skill Training and Family Psychoeducation can improve cognitive, psychomotor and affective school-aged children to prevent bullying behavior. Social Skill Training and Family Psycho education can be developed as a model in the prevention of Bullying behavior in school-aged children.
\end{abstract}

Keywords: Social Skill Training, Family Psycoeducation, Bullying Prevention

\begin{abstract}
ABSTRAK
Bullying seolah-olah sudah menjadi bagian yang tak terpisahkan dari kehidupan anak-anak di zaman sekarang. Tingginya kejadian perilaku bullying pada anak usia sekolah dasar di lingkungan keluarga, sekolah, maupun lingkungan sekitar menunjukkan kebutuhan intervensi segera untuk mengatasi masalah anak usia sekolah. Perlu diupayakan usaha-usaha berupa pencegahan (prevensi) maupun penanggulangan (treatment dan rehabilitasi) bagi korban perilaku Bullying. Salah satu bentuk intervensi yang dapat dikembangkan sebagai upaya pencegahan perilaku bullying pada anak usia sekolah adalah terapi Sosial Skill Training dan Family Psicoeducation. Melalui Sosial Skill Training dan Family Psicoeducation dapat meningkatkan kognitif, psikomotor dan afektif anak usia sekolah untuk mencegah perilaku Bullying. Sosial Skill Training dan Family Psicoeducation dapat dikembangkan sebagai model dalam prevensi perilaku Bullying pada anak usia sekolah.
\end{abstract}

Kata Kunci: Social Skill Training, Family Psycoeducation, Prevensi Bullying

\section{PENDAHULUAN}

Maraknya aksi kekerasan dalam bentuk bullying yang dilakukan siswa di sekolah semakin banyak menghiasi deretan berita di halaman media cetak maupun elektronik akhir- akhir ini. Hal ini memuncul kekhawatiran bahwa kekerasan dianggap sebagai suatu hal yang normal dan wajar dalam masyarakat, termasuk kekerasan yang terjadi pada anak. Bullying seolah-olah sudah menjadi bagian yang tak terpisahkan dari kehidupan anak-anak di zaman sekarang, Djuwita, R. (2011) 


\begin{abstract}
Bullying merupakan suatu bentuk perilaku agresif yang diwujudkan dengan perlakuan tidak sopan, pelecehan seksual, penggunaan kekerasan atau paksaan untuk mempengaruhi orang lain, dilakukan secara berulang atau berpotensi untuk terulang, dan melibatkan ke tidak seimbangan kekuatan dan kekuasaan (Afriana,D, 2014).
\end{abstract}

Beberapa hasil penelitian menunjukan bahwa perilaku bullying merupakan masalah serius yang terjadi pada anak. Hasil survey C. S Mott Children's Hospital National diketahui bahwa bullying termasuk kedalam 10 masalah kesehatan yang mengkhawatirkan pada anak Goodwin, D. (2010)

Riset yang dilakukan LSM Plan International dan International Center for Research on Women (ICRW) tahun 2015 di tingkat Asia, kejadian bullying pada siswa di sekolah mencapai angka 70\%. Penelitian ini juga menyebutkan bahwa $84 \%$ siswa di Indonesia mengalami kekerasan di sekolah. Lestari, D. (2013).

Kemungkinan fenomena bullying di sekolah dasar akan semakin banyak ditemui, dan menjadi fenomena gunung es. Hal ini dikarenakan kebanyakan orang tua maupun pihak sekolah tidak menyadari bahwa telah terjadi bullying di sekolahnya. Sering kali, perilaku bullying ini luput dari perhatian orang tua maupun pihak sekolah. Umumnya, orang tua dan pihak sekolah beranggapan bahwa saling mengejek, berkelahi, maupun mengganggu anak lain merupakan hal yang biasa terjadi pada anak sekolah dan bukan merupakan masalah serius ( Latifah, 2012).

Menurut Merrell, K.W \& Isava, D.M. (2008) perilaku bullying umumnya disebabkan karena anak ingin mencari perhatian dari orang sekelilingnya, mencoba-coba, terpengaruh oleh teman sebayanya, pengaruh iklan dan media masa, tekanan teman sebaya, sikap pembiaran dari sekolah serta pola asuh orang tua yang otoriter, sehingga ini akan berdampak secara fisik, psikis, dan sosial terhadap korban.

Melihat berbagai dampak yang ditimbulkan akibat perilaku bullying pada anak maka perlu diupayakan usaha-usaha berupa pencegahan (prevensi) maupun penanggulangan (treatment dan rehabilitasi) bagi korban perilaku Bullying. Salah satu 
bentuk intervensi yang dapat dikembangkan sebagai upaya pencegahan perilaku bullying pada anak usia sekolah adalah terapi Sosial Skill Training. Social skills training merupakan sebuah metode berdasarkan prinsip-prinsip sosial dan menggunakan teknik perilaku bermain peran, praktek dan umpan balik dalam upaya meningkatkan kemampuan seseorang dalam menyelesaikan masalah (Kneisl \& Varcarolis, 2008).

Penanganan secara dini perilaku bullying agar terhindar dari masalah serius tidak hanya berasal dari anak sendiri namun dibutuhkan juga dari keluarga. Banyak keluarga yang mengalami stres akibat ketidaktahuan tentang bullying yang dialami anaknya dikarenakan tidak mengetahui masalah dan cara penanganan perilaku bullying

Terapi keluarga yang bisa digunakan dalam mengatasi bullying dapat berupa terapi family psikoeducation (Stuart 2013).Terapi ini berupa pemberian informasi dan edukasi melalui komunikasi terapiutik yang melibatkan keluarga. Dengan pemberian family psikoeducation diharapkan keluarga memahami masalah yang dialami oleh anggota keluarga, mampu mengatasi masalah pada diri sendiri yang muncul karena adanya anggota keluarga dengan perilaku bullying dan mampu mengatasi beban dan memanfaatkan sarana di komunitas.

$$
\text { Data statistik Komisi }
$$
Perlindungan Anak Indonesia (KPAI) menyebutkan terdapat peningkatan kasus kekerasan yang diterima oleh KPAI Nasional dalam lima tahun terakhir Pada tahun 2011 terdapat 2.413, di tahun 2012 meningkat menjadi 2.508, di tahun 2013 meningkat 2.637, tahun 2014 bertambah tinggi yaitu 2.792 dan tahun 2015 sebanyak 3.339 kasus dan kasus kekerasan anak lainnya yang belum tercatat di KPAI. (Sirait, 2016).

Komisi Perlindungan Anak Indonesia (KPAI) Sumatera Barat tahun 2016 melaporkan bahwa daerah yang paling banyak mengalami Bullying adalah kota Padang, Payakumbuh dan Kota Solok dengan prevelansi diatas $71 \%$ siswa pernah mengalami kekerasan di sekolah (bullying). $57 \%$ anak pernah mengalami tindakan bullying baik itu secara langsung maupun tidak langsung.

Peneliti melakukan penelitian di Sekolah Dasar Negeri No 05 Surau 
Gadang Kecamatan Nanggalo Kota

Padang yang sudah terakreditasi

B. Sekolah Dasar Negeri No 05 Surau

Gadang terletak Jalan Raya Siteba

Surau Gadang Nanggalo Kota Padang,

kawasan padat dan berdekatan dengan

panggalan becak motor dan angkot

Sekolah Dasar ini terdiri dari 12 kelas, dengan jumlah murid 362 orang.

Belum pernah dilakukannya

Social skills training (SST) dan family psikoeducation pada anak usia sekolah di kota Padang dalam pencegahan perilaku bullying, menjadi latar belakang perlunya dilakukan Social skills training (SST) dan family psikoeducation pada anak usia sekolah dasar di kota Padang khususnya SDN 05 Surau Gadang Nanggalo Kota Padang, oleh karena itu peneliti melakukan penelitian tentang "Penerapan Social Skill Training Dan Family Psycoeducation Dalam Prevensi Perilaku Bullying Pada Siswa Sekolah Dasar Di Kota Padang”.

\section{METODOLOGI}

Penelitian menggunakan pendekatan riset kuantitatif dengan "Quasi Experimental pre and post test with control group" dengan Terapi Social Skill Training dan Family Psicoeducation. Dilaksanakan di SDN
05 Nanggalo Kota Padang pada bulan Maret sampai November 2017. Sampel adalah siswa SDN 05 Nanggalo Kota Padang TA 2017/2018 sebanyak 62 orang. Pengambilan sampel secara purposive sampling. Alat pengumpul data menggunakan Kuesioner. Kuesioner ini diisi dengan menuliskan jawaban dan memberikan tanda checklist $(\sqrt{ })$ pada pernyataan yang sesuai dengan kondisi responden.Untuk mengukur perilaku bullying pada anak usia sekolah dasar peneliti mengelompokan pernyataanpernyataan tersebut kedalam beberapa sub variabel, yaitu pelaku dan korban bullying untuk masing-masing jenis bullying fisik, verbal, dan psikososial.

Guna menjaga validitas dan reliabilitas instrumen penelitian dilakukan terlebih dahulu uji coba instrumen pada 10 orang SDN 06 Padang yang memiliki karakteristik yang hampir sama dengan responden. Uji validitas menggunakan pearson product moment dengan hasil apabila nilai $\mathrm{r}$ antara masing-masing item pernyataan lebih besar atau sama dengan 0,5 . Uji reliabilitas dilakukan dengan menggunakan Internal Consistency yang dilihat pada nilai Alpha Cronbach. Jika nilai koefisien

18 Jurnal Pembangunan Nagari | Volume 3 Nomor 2 Edisi Desember 2018 : 15 - 23 
reliabilitas $\mathrm{r}$ mendekati 1 , maka setiap skor responden dapat dipercaya atau reliabel.

Sebelum penelitian dilakukan terlebih Kaji Etik melalui Komisi Etik Penelitian untuk memenuhi etika dan mendapatkan persetujuan melakukan penelitian dari Dinas Pendidikan Kota Padang dan SDN 05 Surau Gadang Nanggalo Siteba Padang. Sebelum dilakukan intervensi dilakukan Pre test mengukur Perilaku Bullying, harga diri dan asertifitas pada dua kelompok yakni kelompok yang diberikan social skill training dan modul family psicoeducation dan kelompok yang hanja mendapatkan social skill training. Tahapan intervensi untuk kelompok Pertama diberikan social

\section{HASIL DAN PEMBAHASAN}

Hasil

Tabel 1: Distribusi Responden berdasarkan Kelompok Kontrol dan Intervensi di Sekolah Dasar 05 di Kota Padang Tahun 2017

\begin{tabular}{cllll}
\hline $\begin{array}{c}\text { Kelompok } \\
\text { Intervensi } \\
(\mathrm{N}=31)\end{array}$ & $\begin{array}{c}\text { Pelaku } \\
6(19,3 \%)\end{array}$ & $\begin{array}{c}\text { Korban } \\
13(41,9 \%)\end{array}$ & $\begin{array}{c}\text { Saksi } \\
7(22,6 \%)\end{array}$ & $\begin{array}{l}\text { Tidak Pelaku Korban } 5(16,2 \%) \\
\text { Saks }\end{array}$ \\
\hline $\begin{array}{c}\text { Kelompok } \\
\text { Kontrol }\end{array}$ & Pelaku & Korban & Saksi & Tidak Pelaku Korban \\
$(\mathrm{N}=31)$ & $125,8 \%)$ & $12(38,7 \%)$ & $6(19,3 \%)$ & Saksi 5 (16,2\%) \\
\hline
\end{tabular}

Berdasarkan tabel 1 pada kelompok kontrol pelaku terdapat $25,8 \%$ dengan korban $38,7 \%$ dan pada kelompok intervensi terdapat $19,3 \%$ pelaku dan $41,9 \%$ adalah korban. skill training dan family psicoeducation dalam 5 sesi dalam 5 (lima kali kunjungan selama 4 (empat) minggu).Tiap sesi dilakukan selama 60-90 menit. Untuk kelompok dua hanja diberikan social skill training.Tahapan Pos Post test dilakukan pada kelompok intervensi dan kelompok kontrol setelah semua sesi dalam intervensi selesai. Pos test dilakukan untuk pengukuran kognitif, afektif dan psikomotor responden dalam prevensi bullying segera setelah perlakuan. Analisa data dilakukan secara univariat dengan descriptive statistics dan bivariate menggunakan independent test, sample T-test dan ANOVA test. 
Tabel 2: Rerata Prevensi Bullying Setelah Diberikan Tindakan di SDN 05 Kota Padang Tahun $2017(\mathrm{n}=62)$

\begin{tabular}{|c|c|c|c|c|c|c|c|}
\hline \multirow{2}{*}{\multicolumn{2}{|c|}{ Prevensi }} & \multicolumn{3}{|c|}{$\begin{array}{l}\text { Kelompok Intervensi } \\
(\mathrm{n}=31)\end{array}$} & \multicolumn{3}{|c|}{ Kelompok Kontrol $(n=31)$} \\
\hline & & Mean & SD & Min-mak & Mean & SD & Min- mak \\
\hline $\begin{array}{l}\text { 1. Kognitif } \\
\text { terhadap }\end{array}$ & $\begin{array}{r}\text { siswa } \\
\text { Prevensi }\end{array}$ & 10.48 & 2.987 & $5-14$ & 8.10 & 1.446 & $5-11$ \\
\hline $\begin{array}{l}\text { Bullying } \\
\text { 2. Afektif sisw } \\
\text { Prevensi Bull }\end{array}$ & $\begin{array}{l}\text { terhadap } \\
\text { ing }\end{array}$ & 33.06 & 3.162 & $37-51$ & 40.23 & 3.757 & $32-48$ \\
\hline $\begin{array}{l}\text { 3. Psikomotor } \\
\text { terhadap } \\
\text { Bullying }\end{array}$ & $\begin{array}{r}\text { siswa } \\
\text { prevensi }\end{array}$ & 3.10 & 0.944 & $2-5$ & 2.87 & 0.885 & $2-5$ \\
\hline
\end{tabular}

Berdasarkan tabel 2 rata rata kognitif dan psikomotor siswa terhadap prevensi bullying lebih tinggi pada kelompok intervensi yang dilakukan Sosial Skill Training dan psikoedukasi keluarga $(10,48)$ untuk kognitif dan 3,10 untuk psikomotor dibandingkan kogniti dan psikomotor siswa yang hanja diberikan terapi Sosial Skill Training.

Tabel 3: Rerata Perbedaan Prevensi Bullying sebelum \& Setelah Tindakan Pada Kelompok Intervensi dan Kontrol di SDN 05 Kota Padang Tahun $2017(\mathrm{n}=62)$

\begin{tabular}{|c|c|c|c|c|c|}
\hline $\begin{array}{l}\text { Prevensi } \\
\text { Bullying }\end{array}$ & Kelompok & Mean sesudah & Mean sebelum & Selisih & Pvalue \\
\hline $\begin{array}{l}\text { Kognitif siswa } \\
\text { terhadap prevensi } \\
\text { Bullying }\end{array}$ & $\begin{array}{c}\text { Intervensi } \\
\text { Kontrol }\end{array}$ & $\begin{array}{c}10.48 \\
2.71\end{array}$ & $\begin{array}{l}6.10 \\
1.90\end{array}$ & $\begin{array}{l}4.38 \\
0.81\end{array}$ & 0.000 \\
\hline $\begin{array}{l}\text { Afektif Siswa } \\
\text { terhadap prevensi } \\
\text { Bullying }\end{array}$ & $\begin{array}{c}\text { Intervensi } \\
\text { Kontrol }\end{array}$ & $\begin{array}{l}44.84 \\
40.00\end{array}$ & $\begin{array}{c}33.06 \\
29.84\end{array}$ & $\begin{array}{l}11.78 \\
10.16\end{array}$ & 0.013 \\
\hline $\begin{array}{l}\text { Psikomotor siswa } \\
\text { terhadap Prevensi } \\
\text { Bullying }\end{array}$ & $\begin{array}{c}\text { Intervensi } \\
\text { Kontrol }\end{array}$ & $\begin{array}{l}3.10 \\
2.87\end{array}$ & $\begin{array}{l}2.06 \\
2.03\end{array}$ & $\begin{array}{l}1.04 \\
0.84\end{array}$ & 0.038 \\
\hline
\end{tabular}

Berdasarkan tabel.3 diketahui bahwa rata-rata kognitif siswa terhadap prevensi bullying pada kelompok yang diberikan Sosial Skill Training dan Program Psikoedukasi Keluarga dengan kemampuan kognitif siswa pada kelompok yang hanja diberikan Sosial Skill Training terlihat ada perbedaan. Hasil uji statistik menunjukkan ada peningkatan kemampuan kognitif dalam prevensi bullying sebelum dan sesudah diberi Sosial Skill Training dan program psiko edukasi keluarga dengan nilai $\mathrm{p}=0,000$ ( $\mathrm{P}$ Value $<0,05$ ). Hasil uji statistik menunjukkan ada peningkatan kemampuan afektif dan psikomotor dalam prevensi bullying sebelum dan sesudah diberi Sosial Skill 
Training dan Psiko Edukasi Keluarga dengan nilai $\mathrm{p}<0,05$.

\section{Pembahasan}

Hasil analisis menunjukkan kognitif, afektif dan psikomotor anak usia sekolah yang mengikuti Sosial Skill Training dan Psiko Edukasi Keluarga meningkat secara bermakna dalam prevensi Bullying pada anak usia sekolah dengan $\mathrm{P}$ value $<0,05$ ) Kognitif, afektif dan psikomotor anak usia sekolah yang mengikuti Sosial Skill Training dan Psikoedukasi Keluarga terlihat lebih tinggi dibandingkan dengan anak usia sekolah yang hanja mendapatkan Sosial Skill Training. Berdasarkan hasil penelitian didapatkan peningkatan pengetahuan dan perbaikan sikap terhadap prevensi bullying yang paling baik, didapatkan siswa sekolah dasar yang mendapatkan Sosial Skill Training dan Psiko Edukasi Keluarga.

Hasil penelitian yang didapatkan sebagian besar siswa Sekolah Dasar menganggap bahwa pemahaman tentang perilaku bullying lebih kepada hal - hal yang berbau kekerasan, terlebih kepada tindakan yang menyakiti secara fisik, sementara menggunakan nama julukan yang buruk, kata - kata kasar dalam bergaul dianggap sebagai candaan dan salah satu cara agar mental menjadi kuat.

Peneliti menganalisis bahwa sebagian besar siswa Sekolah Dasar tidak memiliki pengetahuan yang cukup tentang perilaku Bullying, baik itu kekerasan fisik, verbal dan relasional.Siswa beranggapan julukan julukan yang diberikan ketemannya merupakan hal yang wajar dan biasa.

Hasil penelitian melaporkan Social Skills Training yang diberikan pada siswa sekolah dasar dalam pencegahan perilaku bullying dapat meningkatkan kemampuan siswa Sekolah Dasar berinteraksi dengan temannya dan mampu mempertahankan hubungan yang baik dengan temanya. Social skills training merupakan suatu proses belajar dimana seseorang belajar cara fungsional dalam berinteraksi dan menggunakan teknik perilaku bermain peran, praktek dan unpan balik untuk meningkatkan kemampuan menyelesaikan masalah dalam kelompok. (Videbeck 2006).

$$
\text { Peningkatan kemampuan }
$$
kognitif dan psikomotor Siswa Sekolah Dasar karena informasi yang diberikan dikomunikasikan dengan 
baik kemudian siswa dilatih untuk mempraktekkan cara baru yang diajarkan lalu dilatih melakukan setiap hari sesuai jadwal aktifitas harian yang disepakati. Hal ini juga didukung dengan pemberian psikoedukasi keluarga .

Keluarga merupakan elemen penting dalam memberikan dukungan sosial pada siswa. Hal ini terjadi dikarenakan keluarga mampu memberikan ketenangan, berdasarkan agama dan keyakinan yang dianut oleh sesama anggota keluarga. Sehingga keluarga merupakan pendukung sosial yang sangat baik anggota keluarga

Hasil penelitian yang telah dilakukan membuktikan Sosial Skill Training dan psikoedukasi keluarga berpengaruh dalam meningkatkan kognitif, afektif dan psikomotor siswa dalam prevensi Bullying dibandingkan dengan siswa hanja diberikan Sosial Skill Training. Peningkatan kemampuan kognitif, afektif dan psikomotor siswa didukung pelaksanaan latihan dikomunikasikan secara terbuka dengan siswa, kontrak yang jelas dan pemberian reinforment positif senantiasa diberikan kepada siswa.

\section{KESIMPULAN}

Berdasarkan hasil penelitian dapat disimpulkan bahwa ada penurunan bermakna rata-rata perilaku bullying siswa Sekolah Dasar sebelum dan sesudah diberi Sosial Skill Training dan psiko edukasi keluarga. Hasil analisis menunjukkan kognitif, afektif dan psikomotor anak usia sekolah yang mengikuti Sosial Skill Training dan Psiko Edukasi Keluarga meningkat secara bermakna dalam prevensi Bullying pada anak usia sekolah dengan $\mathrm{P}$ value $<0,05)$. Peningkatan kemampuan kognitif, afektif dan psikomotor siswa Sekolah dasar terhadap prevensi bullying yang paling baik, didapatkan siswa sekolah dasar yang mendapatkan Social Skill Training dan Psiko Edukasi Keluarga.

\section{REKOMENDASI}

Direkomendasikan perawat yang bekerja di puskesmas khususnya pemegang program UKS perlu mendapatkan pelatihan tentang Social Skill Training dan Psiko Edukasi Keluarga agar dapat menerapkannya pada kegiatan UKS pada kelompok Anak usia sekolah dalam Prevensi Bullying dengan berpedoman kepada modul Social Skill Training dan Psiko Edukasi Keluarga yang telah ada. 
Melalui Dinas Pendidikan Kota

Padang agar bisa merekomendasikan guru Sekolah Dasar khususnya guru kelas mendapatkan pelatihan tentang Social Skill Training dan Psiko

\section{DAFTAR PUSTAKA}

Afriana, D. (2013). Upaya Mengurangi Perilaku Bullying Di Sekolah Dengan Menggunakan Layanan Konseling Kelompok. Fakultas Keguruan Dan Ilmu Pendidikan, $1-15$

Djuwita, R. (2011). Penanggulangan bullying di sekolah. Membentuk Masyarakat Indonesia yang Resilien Melalui Pendidikan Karakter: Psychology Expo 2011, Jakarta, Indonesia.

Goodwin, D. (2014). Strategis To Deal With Bullying (Strategi Mengatasi Bullying) Alih Bahasa : Cicilia Evi Graddiplsc., M.Psi. Wellington Australia : Kidsrearch Inc

Kneisl, C.R., Wilson, H.S., \& Trigoboff, E. (2004). Contemporary Psychiatry Mental Health Nursing. New Jersey : Pearson Prentice Hall

Latifah ( 2012) Hubungan Karakteristik Anak Usia Sekolah Dengan Kejadian Bullying Di Sekolah Dasar X Di Bogor. Skripsi

Lestari, D. (2013). Menurunkan Perilaku Bullying Verbal Melalui Pendekatan Konseling Singkat
Edukasi Keluarga dengan berpedoman kepada modul yang telah ada.

Berfokus Solusi. Jurnal Pendidikan Penabur, 21-36

Merrell, K.W \& Isava, D.M. (2008). How Effective Are School Bullying Intervention Programs? A Meta-Analysis of Intervention Research. Apa School Psychology Quarterly, 23 (1):26-42

Renidayati. (2016). Pengaruh Social Skills Training (SST) dan psikoedukasi keluarga pada anak dengan perilaku kekerasan. Penelitian. Poltekkes Kemenkes Padang

Siswati \& Widayanti. (2009). Fenomena Bullying Di Sekolah Dasar Negeri Di Semarang:Sebuah Studi Deskriptif. Jurnal Psikologi Undip, 5 (2)

Sercombe and Donnelly,B. (2013). Bullying And Agency : Definition, Intervention, And Ethics. Journal Of Youth Studies (Routledge Taylor \& Francis Group), 16 (4):491-502

Stuart, G.W. (2013). Principles and Practice of Psychiatric Nursing. China: Elsevier Inc.

Stuart,G.W \& Laraia, M.T (2010). Principles and Practice of psychiatric nursing. (7th edition). St Louis: Mosby. 